\title{
ASHS Strategic Planning and HortBase
}

Mary Lewnes Albrecht

Summary. The ASHS Strategic Plan consists of four key result areas. Key Result Area One: Enhance Internal Services, identifies various aspects of communication with and enhancing services for the membership. Strategy Three calls for the development of an information highway through advanced communication technologies. Strategy Four seeks to enhance services for international members and Strategy Five and Six addresses increasing the involvement of graduate and undergraduate students and increasing the value of membership to diverse members. There are various other aspects of the Strategic Plan dealing with promoting horticulture and horticulture information dissemination that are affected by HortBase. How the development and implementation of HortBase will help ASHS reach these objectives is discussed.

$\mathrm{O}$ n 28 July 1993 the members of ASHS adopted the strategic planning document, "Leading Horticultural Science into the 21st Century: A Strategic Plan Through the Year 2003" (ASHS, 1993). The strategic plan defined the mission of ASHS as advancing the knowledge and application of horticultural science by nurturing the diversity of professionals in horticulture, serving as a primary source of scientific information, and fostering the education of the next generation of horticulturists. HortBase directly relates to our mission as a professional society. HortBase allows members of ASHS to share knowledge with different horticulture audiences and can be used as a tool for future horticulturists.

The mission statement went on to state that "Our constituents are individuals and organizations who create, apply, and impart knowledge to improve horticultural systems, environmental sustainability, and human well-being." HortBase is just another means for reaching our constituent groups: horticultural consultants, school teachers, gardeners, landscape professionals, extension personnel from county through state specialists, researchers, community college and university teachers, students, legislators, and other public-policy makers. HortBase directly addresses the needs of the diverse membership and can assist members to disseminate reliable information to end-users.

The ASHS Strategic Plan consists of four Key Result Areas, each with specific strategies (Table 1) and objectives. In 1993, it was envisioned that ASHS initiate Internet access providing communication between members and headquarters staff by means of e-mail, provide archival ASHS publications on CD-ROM, and explore potential of online publication and other forms of electronic communications.

Professor and head, Department of Ornamental Horticulture and Landscape Design, 2431 Center Drive, Room 252, University of Tennessec, Knoxville, TN 37996-4500; , e-mail, mlalbrecht@utk.edu. 
Since 1993, rapid developments in computer technology, telecommunications, Internet use, and changes in organization and management at headquarters, have allowed for realization of many of these specific objectives.

ASHS has been working hard on meeting the objectives linked to the advanced communication technologies. The ASHS World Wide Web (Web) site (http://www.ashs.org) hasinformation regarding ASHS events, membership benefits, headquarterstaff, officers, publications, job opportunities, and other horticulture-related Web sites. A searchable CD-ROM of the past several years of the ASHS journals will be available. List-servers of the working groups and committees are established and being used by members.

HortBase, as an innovative electronic information system, is the next step in using the newest technologies to provide information to horticultural practitioners and consumers. It deals most directly with strategies outlined in Key Result Area One. By going to a peer-reviewed, electronic publication of timely horticultural information, ASHS can coordinate efforts to provide accurate and reliable information to Internet users. A national, peer-reviewed system will provide a measure of credibility and professionalism accepted by university and college administrators. Many university and college evaluation systems are adapting and beginning to recognize and value electronic forms of publication and service.

HortBase will be a way to disseminate information and serve as a horticultural library for Internet users: international members, graduate and under- graduate students, practitioners, other professionals, and consumers. We can minimize duplication of efforts through the use of HortBase. Departments, state extension services, and commercial Web sites can link to it. HortBase will contribute to promoting horticulture.

The modern era of electronic communications is being embraced by the youth of the world. Today, students working in school libraries use the Internet to conduct research for class assignments, and select career paths and make campus visits as part of the college search. As more public and private school systems go online, teachers need sites they can rely upon for accurate and useful information. We can provide information for K through 12 instruction. HortBase can also provide a vehicle for instructors at community colleges and universities to share laboratory exercises and supporting class materials.

HortBase will provide many things to ASHS members and others using the Internet.

1) Refereed publication on the InterNET. By going to a peer-reviewed, electronic publication of timely horticultural information, ASHS can help coordinate efforts to provide accurate and reliable information to Internet users. A national, peer-reviewed system will provide a measure of credibility and professionalism accepted by university and college administrators. Many university and college evaluation systems are adapting and beginning to recognize and value electronic forms of publication and service.

2) Timely dissemination of researchBASED IMFORMATION. HortBase will pro- vide a means to distribute reliable, research-based information to users worldwide. Since the information will be posted on the Internet, it will be available to a wide-range of end-users.

3) ACCESSIBLE TO UNIVERSITY AND INDUSTRY PROFESSIONALS AND THE GENERAL PUbLic. Access will not be limited to those near a comprehensive research library.

4) Horticulture paesence on the InTERnet. Many Web sites deal with gardens and landscapes. Fewer Web sites deal with commercial information. This will not replace the differentcooperative extension serviceWeb sites, but will build on and enhance the information that is already available. Links from cooperative extension service sites to HortBase will provide rapid access to users. Being associated with ASHS and the National Agriculture Library will also provide a level of credibility that some general horticulture sites presently lack.

5. Reaching future horticulturists WITH A MEDIUM WITH WHICH THEY ARE ALREADY FAMILIAR. The future generations are already comfortable surfing the Internet. HortBase is not only about how we get information out to current horticulture practitioners, it is about reaching future generations.

\section{Information resources cited}

American Society for Horticultural Science. 1993. Leading horticultural science into the 21st century: A strategic plan through the year 2003. ASHS Nwslt. $9(9): 4-8$.

Table 1. Key result areas and strategies as outlined in the 1993 ASHS Strategic Plan.

Key result area Strategies

1) Enhance internal services

Improve publication quality, including diversity, user acceptance, competition, and process. Improve educational meetings.

Develop an information highway through advanced communication technologies.

Enhance services for international members.

Increase the membership and involvement of graduate and undergraduate students in ASHS.

Increase the value of membership to diverse members considering gender, ethnic, extension, teaching, industry.

2) Improve management systems

Provide financial stability.

Improve the organization structure of the Society.

Empower staff and volunteers to make necessary changes to meet external opportunities.

3) Promote horticulture

Enhance the visibility of ASHS as a vehicle to promote horticulture.

Lead in development of a plan for U.S. horticultural science programs.

Assume a proactive role in addressing issues of concern to society at large.

4) Revitalize horticultural education Improve the position of horticultural education at K-12 and post-high school levels.

Enrich and extend the outreach of the education of future horticulturists. 